\title{
PENGELOLAAN SUAKA PERIKANAN DANAU BAKUOK KABUPATEN KAMPAR RIAU
}

\author{
Khairul Amri') dan Dadiek Prasetyo') \\ 1) Peneliti pada Pusat Riset Perikanan Tangkap, Ancol-Jakarta \\ 2) Peneliti pada Balai Riset Perikanan Perairan Umum, Mariana-Palembang \\ Teregristrasi I tanggal: 4 Maret 2008; Diterima setelah perbaikan tanggal: 14 April 2008; Disetujui terbit tanggal: 5 Mei 2008
}

\begin{abstract}
ABSTRAK
Danau Bakuok yang terletak di Kabupaten Kampar merupakan salah satu contoh suaka perikanan di Propinsi Riau yang penetapan dan pengelolaannya berdasarkan hukum adat. Berbagai jenis ikan yang memiliki nilai ekonomis penting terdapat di danau ini antara lain ikan patin (Pangasius sp.), ikan lais (Kryptopterus spp.), dan baung (Hemibagrus nemurus sinonim Mystus nemurus), serta ikan motan (Thynnichthys thynnoides) yang merupakan jenis ikan khas Danau Bakuok. Kegiatan penangkapan ikan hanya boleh dilakukan 1 kali dalam 1 tahun yang dinamakan sebagai acara ma'awuo dan dilaksanakan menjelang bulan Ramadhan. Hasil tangkapan ikan setiap tahun cenderung menurun dan diduga telah terjadi penurunan stok sumber daya ikan. Untuk memperbaiki kondisi ini, pada tahun 2004 pemerintah Propinsi Riau melakukan upaya pengkayaan stok (restocking) berupa penebaran benih ikan baung.
\end{abstract}

KATAKUNCl: Danau Bakuok, konservasi perikanan, hukum adat

\section{PENDAHULUAN}

Suaka perikanan yang dahulu disebut sebagai reservat perikanan merupakan bagian dari perairan umum daratan baik berupa danau, rawa, sungai, atau genangan air lainnya yang dilindungi. Kehadiran suaka perikanan bertujuan memberi perlindungan pada ikan dan ekosistem agar dapat selamat dari ancaman kekeringan dan penangkapan, sehingga dapat berfungsi sebagai sumber atau stok induk dan anakan ikan untuk daerah sekitar (Welcomme, 1979). Secara ekologis, suaka perikanan dapat berfungsi sebagai tempat konservasi sumber daya perikanan, melindungi ikan yang sudah langka, sumber plasma nutfah perikanan dan secara alami sebagai sumber benih perairan sekitar.

Keberadaan suaka perikanan secara hukum dijamin berdasarkan pada undang-undang. Dalam Undang-Undang R.I. No.31 tahun 2004 tentang Perikanan Pasal 7 ayat 1q, Suaka Perikanan (Anonimus, 2004a) didefinisikan sebagai suatu luasan tertentu perairan darat atau perairan bahari yang mempunyai bagian tertentu, ikannya tidak boleh ditangkap, yang dikelola untuk melestarikan dan meningkatkan produksi berdasarkan pada stok alami setempat untuk kesejahteraan masyarakat setempat. Penetapan suaka perikanan dilakukan oleh Menteri dalam hal ini Menteri Kelautan dan Perikanan. Dengan demikian, keberadaan suaka perikanan secara hukum dijamin berdasarkan pada undang-undang.

Suaka perikanan yang terdapat di Indonesia sampai saat ini pada umumnya kurang memenuhi persyaratan untuk peningkatan produksi perikanan perairan umum daratan (Utomo et al., 2001). Dari segi jumlah pun sangat kurang bila dibanding dengan total luasan perairan umum daratan yang ada.

Belum semua suaka perikanan yang terdapat di Indonesia ditetapkan secara resmi sebagai kawasan suaka perikanan berdasarkan Undang-Undang No.31 tentang perikanan yang penetapannya berdasarkan Surat Keputusan Menteri yang berwenang. Sebagian suaka perikanan di daerah tertentu ditetapkan berdasarkan Surat Keputusan Kepala Daerah (Bupati, Walikota, atau Gubernur) dan sebagian lagi merupakan suaka perikanan yang penetapan dan pengelolaan berdasarkan pada hukum adat.

Propinsi Riau merupakan salah satu daerah yang memiliki perairan umum daratan yang cukup luas dengan beragam jenis sumber daya perikanan potensial. Luas perairan umum daratan yang terdapat di Propinsi Riau mencapai 296.506 ha yang terdiri atas danau 22.955 ha, rawa 181.006 ha, dan sungai 92.545 ha. Potensi perairan umum daratan tersebut baik dari sungai, rawa, dan danau adalah 14.232 ton per tahun dan telah dimanfaatkan lebih dari $96,73 \%$ (Dahril, 2007).

Sebagaimana pada umumnya daerah yang memiliki perairan umum daratan, Propinsi Riau juga memiliki kawasan suaka perikanan. Danau Bakuok merupakan salah satu contoh suaka perikanan di propinsi ini, yang penetapan dan pengelolaannya berdasarkan hukum adat. Namun, sampai saat ini sangat sedikit penelitian dan literaturyang membahas tentang suaka perikanan Danau Bakuok, sehingga cukup sulit mendapatkan informasi yang lengkap 
tentang perairan ini. Tulisan ini mencoba menggambarkan kondisi dan pola pengelolaan suaka perikanan Danau Bakuok sebagai pelengkap informasi tentang danau dimaksud.

\section{KONDISI DANAU BAKUOK}

Danau Bakuok terletak di Desa Aursati, Kecamatan Tambang, Kabupaten Kampar dengan posisi geografis berada pada koordinat 00.21.47.3 LU dan 101.15.57.6 BT (Gambar 1). Danau ini berada sekitar $50 \mathrm{~km}$ arah barat daya Kota Pekanbaru. Jalan masuk menunju danau ini berada di Kecamatan Tambang sebelah kiri jalan dari arah Pekanbaru menuju Bangkinang, jarak ke dalam sekitar 6 km dari jalan lintas propinsi.

Danau Bakuok berbentuk memanjang ke arah utara-selatan sejalan dengan arah aliran air Sungai Kampar (Gambar 2). Lokasinya berada persis pada bagian sisi timur Sungai Kampar dan berukuran kurang lebih 1.000×100 m dengan panjang keliling danau sekitar 1,5 km (Anonimus, 2005). Sungai Kampar ini merupakan salah satu sungai penting di Riau yang juga dimanfaatkan sebagai sarana transportasi air dan memiliki panjang sekitar $400 \mathrm{~km}$ dengan kedalaman rata-rata $6 \mathrm{~m}$.

Danau Bakuok merupakan jenis danau oxbow (danau banjiran atau sungai mati). Danau ini terbentuk melalui pemutusan aliran sungai akibat proses alami berupa pengendapan Sungai Kampar yang lokasinya terjadi persis di Desa Aursati. Secara ekologis, sekaligus telah merubah ekosistem perairan tersebut dari yang semula berupa perairan mengalir (dalam bentuk sungai) menjadi ekosistem air tergenang (dalam bentuk danau). Secara fisik, terlihat bahwa Danau Bakuok telah kehilangan hubungan langsung dengan Sungai Kampar. Namun, hubungan ekologis keduanya kembali dapat terjadi manakala terjadi banjir sehingga air Sungai Kampar melimpas dan memasuki Danau Bakuok.

Kedalaman danau berkisar 4 - 6 m pada bagian yang dalam lokasinya di tengah danau dan sekitar 2 - $3 \mathrm{~m}$ pada bagian pinggiran. Ketika musim kemarau (Mei - Agustus), volume air danau menyusut seiring berkurangnya suplai air dan sebaliknya ketika musim hujan (Nopember - Januari), volume air danau meningkat seiring terjadi limpasan air (banjir) Sungai Kampar. Air danau terlihat berwarna coklat agak kemerahan dan cenderung keruh ketika musim hujan.

Pada salah satu sisi danau sebelah timur terdapat jalan yang dapat dilalui kendaraan bermotor roda 2 dan 4 dengan kondisi jalan yang relatif baik. Pada bagian pinggir danau pada sisi timur ini ditumbuhi berbagai pohon besar dan perdu. Pada sisi danau bagian barat yang berdampingan dengan Sungai Kampar ditumbuhi dengan semak belukar sebagai tanaman liar. Sebagian sistem riparian danau (tepi danau yang berair) terdapat tanaman air berupa jenis rumput terendam (flooded grass land) yang terdiri atas aneka rerumputan yang tahan rendaman air. Jenisjenis rerumputan ini banyak terdapat sepanjang sisi barat danau dan terlihat tumbuh subur (Gambar 3).

\section{SUMBER DAYAIKAN}

Danau Bakuok merupakan danau yang memiliki sumber daya ikan dengan keragaman jenis dan tingkat produktivitasnya cukup tinggi (Dinas Perikanan

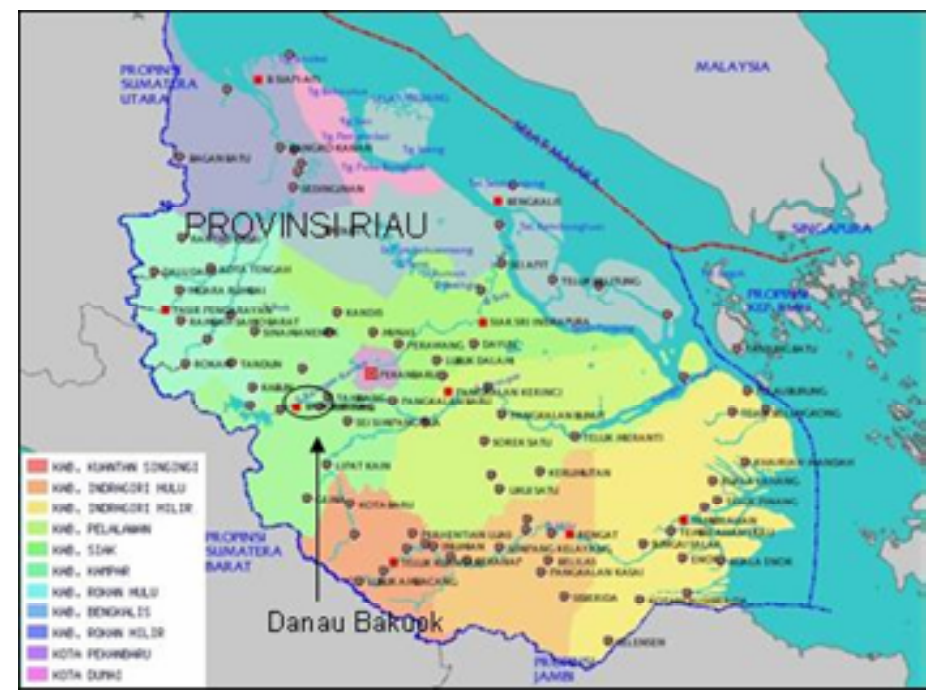

Gambar 1. Peta Propinsi Riau dan lokasi Danau Bakuok. 


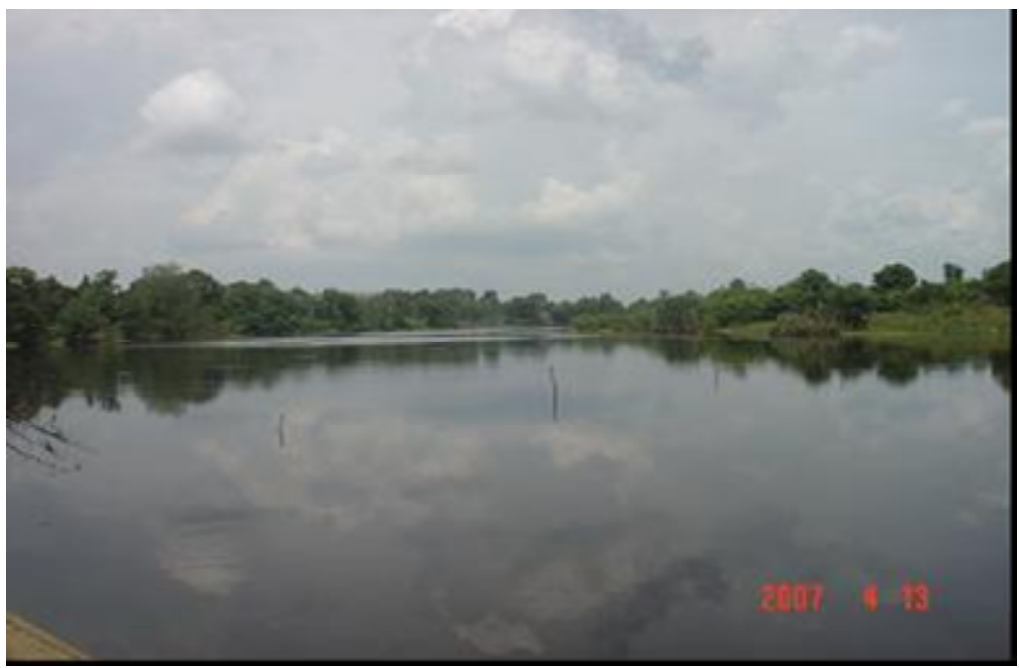

Gambar 2. Bentuk Danau Bakuok memanjang di pinggiran Sungai Kampar.

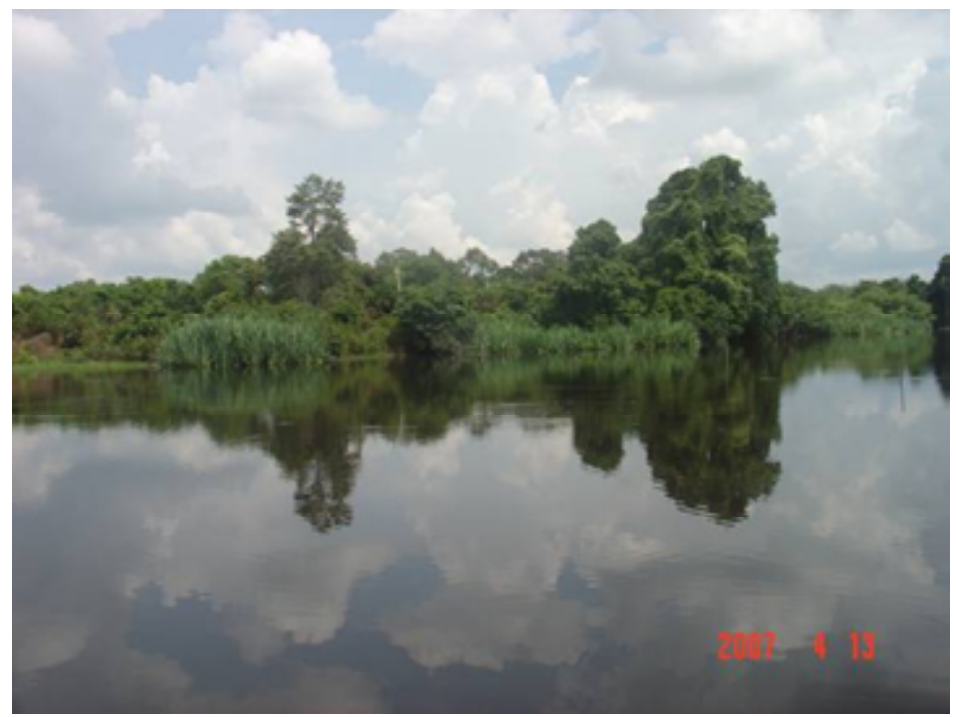

Gambar 3. Beberapa jenis tanaman yang terdapat di Danau Bakuok.

Kampar: komunikasi pribadi, 2007). Sudah sejak lama Danau Bakuok dijadikan sebagai sumber ikan, khususnya bagi masyarakat di sekitar danau maupun masyarakat Bangkinang pada umumnya.

Berdasarkan pada pengamatan lapangan dan studi literatur menunjukkan bahwa pada umumnya ikanikan di Danau Bakuok didominasi oleh jenis-jenis ikan perairan umum, khususnya jenis-jenis ikan sungai. Sebagian besar dari jenis-jenis ikan yang terdapat di danau ini merupakan jenis-jenis ikan konsumsi dan memiliki nilai ekonomis penting dengan harga jual yang tinggi. Jenis ikan yang dominan adalah ikan patin (Pangasius sp.), ikan lais (Kryptopterus spp.), dan baung (Hemibagrus nemurus sinonim Mystus nemurus). Ikan motan (Thynnichthys thynnoides) merupakan jenis ikan khas danau ini.

\section{SUAKA PERIKANAN}

Danau Bakuok merupakan suaka perikanan yang dijalankan berdasarkan sistem atau hukum adat. Sampai sejauh ini belum ada surat keputusan resmi yang dikeluarkan pemerintah kabupaten atau propinsi yang dijadikan dasar penetapan Danau Bakuok sebagai kawasan konservasi perikanan (Komunikasi pribadi: Dinas Perikanan Kabupaten Kampar, 2007). Sungguh pun demikian, disebutkan bahwa kondisi sumber daya ikan di danau ini terjaga dengan baik.

Penangkapan ikan di danau ini dilakukan 1 kali 1 tahun (sekitar September setiap tahun) dan menjelang bulan Ramadhan. Kegiatan penangkapan ikan yang dilakukan secara serentak dan melibatkan seluruh masyarakat ini disebut dengan Ma'awuo (Anonimus, 
2005). Sepanjang masa di luar hari Ma'awuo, masyarakat dan siapa pun dilarang menangkap ikan di danau ini. Sehingga oleh masyarakat sekitar Danau Bakuok ini disebut juga sebagai Danau Larangan.

Pengaturan larangan menangkap ikan, waktu penangkapan ikan, pemanfaatan hasil tangkapan ikan dan bahkan kegiatan apa yang akan dilaksanakan di danau ini dikendalikan Pemangku Adat Kenegerian Tambang yang diawasi oleh Ninik Mamak Pesukuan Kenegarian Tambang. Apabila ada yang melanggar (menangkap ikan di luar masa ma'awuo) akan dikenakan denda. Besar dan jenis denda yang dikenakan terhadap pelanggar ketentuan tersebut diputuskan secara musyawarah oleh Pemangku Adat, berupa hewan ternak kambing atau kerbau.

Tradisi berupa perlindungan sumber daya ikan dan pola pemanfaatan secara bersama ini telah berlangsung sejak ratusan tahun lalu. Semula kegiatan ini dilaksanakan pada skala kecil, setingkat kenegerian. Seiring dengan perkembangan masyarakat, hal ini semakin maju dan dikenal luas, bahkan sampai dengan ke luar Kenegerian Tambang. Tak kalah pentingnya, bahkan telah dikembangkan menjadi even tahunan berupa pesta rakyat yang dilengkapi berbagai kegiatan selain kegiatan Ma'awuo yang menjadi soko aktivitas dan dibuka oleh pejabat daerah seperti Gubernur atau Bupati (Anonimus, 2005).

Pada saat kegiatan Ma'awuo (Gambar 4), masyarakat mengambil ikan secara bebas dan gratis semaksimal mungkin (tanpa dibatasi). Diinformasikan bahwa pada saat tersebut masyarakat sengaja mendirikan tenda untuk menetap di sekitar danau selama masa ma'awuo (rata-rata selama 7 hari) dengan melibatkan anggota keluarga. Selain itu, masyarakat Kabupaten Kampar juga ada peserta yang berasal dari luar daerah bahkan dari luar propinsi yakni dari Sumatera Barat.
Penangkapan ikan dilakukan menggunakan jala dan untuk penangkapan ikan di bagian tengah danau menggunakan perahu atau sampan. Kegiatan menangkap ikan melibatkan seluruh anggota keluarga di mana kaum laki-laki bertugas menebar jala, sementara kaum perempuan dan anak-anak berada di pinggir danau menyambut hasil tangkapan. Ikan hasil tangkapan selain dikonsumi sendiri juga untuk dijual. Berbeda dengan tradisi lubuk larangan, seperti yang terdapat di Sumatera Barat dan Sumatera Utara, yang memanen ikan secara bersama-sama dan dibagi rata, sedangkan ikan tangkapan Maa'wuo menjadi hak para penangkap. Dalam tradisi Ma'awuo terdapat prinsip, siapa yang banyak menangkap ikan dia yang akan beruntung (Anonimus, 2008).

\section{FASILITAS PENDUKUNG}

Sebagai kawasan suaka perikanan yang dikelola secara adat, Danau Bakuok tidak dijaga dengan menempatkan penjaga khusus, tetapi dijaga secara kolektif oleh masyarakat dan pola yang demikian ini terbukti efektif. Hal ini sejalan seperti yang dikatakan Hartoto et al. (1998) bahwa faktor yang dianggap paling penting dalam menjamin kesuksesan pengelolaan suaka perikanan di Indonesia yaitu faktor persepsi dan interaksi masyarakat. Di Danau Bakuok pemahaman dan keikutsertaan masyarakat secara luas telah berhasil menjaga keberlangsungan suaka perikanan.

Suaka perikanan sistem adat Danau Bakuok ini sudah memiliki sejumlah fasilitas pendukung. Selain fasilitas jalan yang relatif baik, pada salah satu bagian danau terdapat bangunan yang menjadi tempat pelaksanaan upacara Ma'awuo berbentuk rumah (Gambar 5). Rumah ini sekaligus merupakan pos penjagaan kolektif masyarakat tetapi tidak ditempati secara khusus (hanya pada acara Ma'awuo). Pada pinggiran danau dekat lokasi berdiri rumah terdapat dermaga yang dimanfaatkan sebagai tempat acara

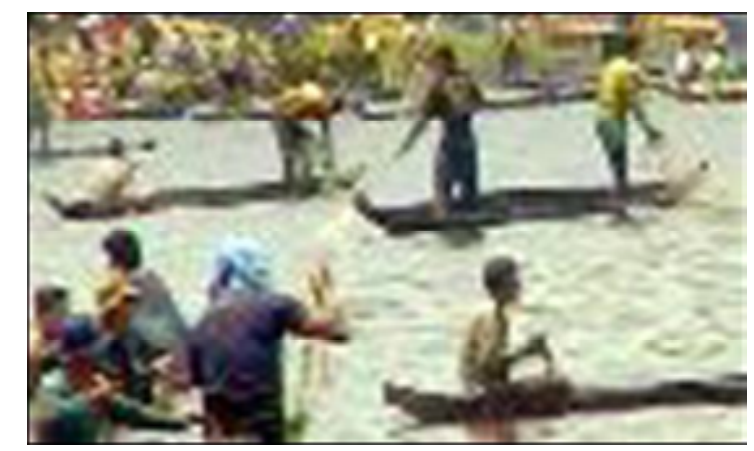

Gambar 4. Kegiatan ma'awuo di Danau Bakuok.

Sumber: www.liputan6.com/tanggal 3 September 2007 


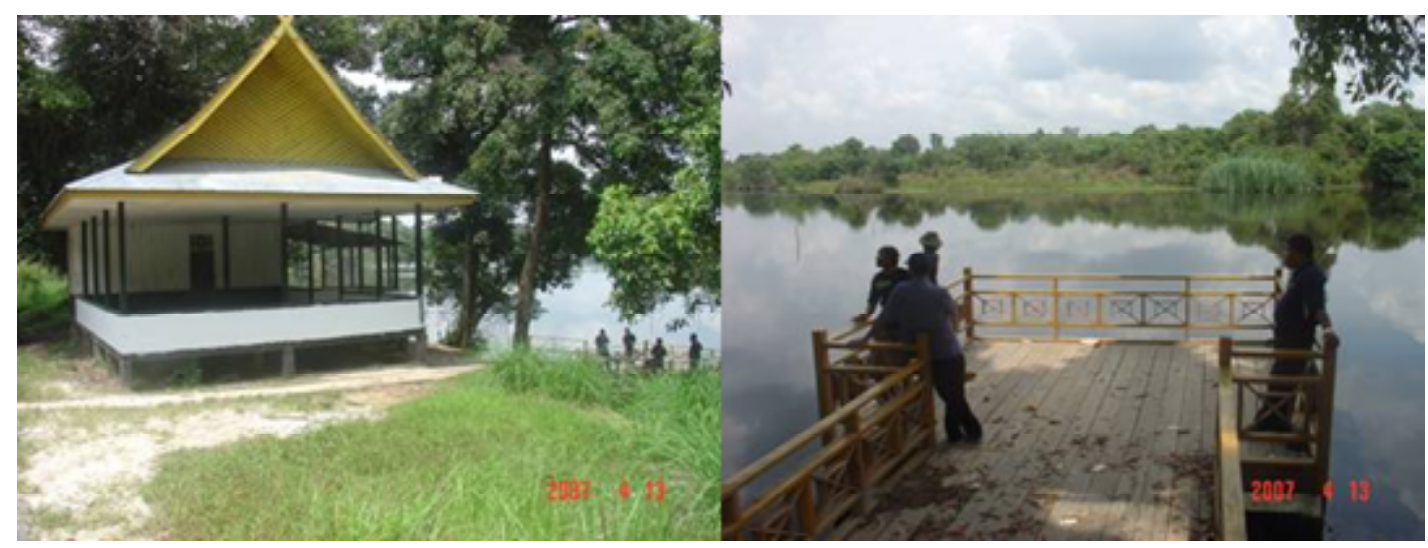

Gambar 5. Fasilitas pengawasan kawasan suaka adat Danau Bakuok berupa rumah jaga dan dermaga di salah satu sisi danau.

pembukaan upacara Ma'awuo secara resmi oleh pejabat pemerintah. Tidak terdapat papan nama yang mengatakan bahwa lokasi tersebut sebagai kawasan konservasi. Demikian juga, mengenai dokumen resmi yang menyebutkan batasan-batasan yang jelas Danau Bakuok serta pembagian wilayah danau sebagai layaknya kawasan konservasi.

\section{PENGKAYAAN SUMBER DAYAIKAN}

Dulu hasil tangkapan masing-masing keluarga yang mengikuti acara Ma'awuo dapat mencapai 50$100 \mathrm{~kg}$, tetapi saat ini hanya sekitar $5 \mathrm{~kg}$ (Anonimus, 2007). Untuk mengembalikan kondisi Danau Bakuok terkait dengan upaya perbaikan kondisi sumber daya ikan, pada tahun 2004, pemerintah dalam hal ini Dinas Perikanan dan Kelautan Propinsi Riau telah melakukan penaburan benih ikan (restocking). Restocking yang dilakukan di Danau Bakuok ini dalam konsep culture base fisheries (Anonimus, 2004b).

Culture base fisheries adalah pengelolaan perairan tawar (danau atau sungai) oleh kelompok masyarakat setempat secara terpadu dengan memanfaatkan perairan tersebut sebagai wadah budi daya bersama secara umum untuk meningkatkan perikanan tangkap (De Silva, 2002).

Dipilihnya Danau Bakuok sebagai lokasi pelaksanaan restocking antara lain karena pertimbangan bahwa kawasan perairan ini telah dikelola secara baik oleh masyarakat sendiri sejak lama. Jenis ikan yang ditebar adalah ikan baung (Mystus nemurus) yang merupakan jenis ikan lokal yang telah ada dan berkembang dengan baik di perairan ini. Jumlah benih ikan baung yang ditebarkan adalah 62.500 ekor dengan ukuran 2-3 inci. Dengan penebaran benih ikan tersebut diharapkan masyarakat dapat meningkatkan produksi ikan perairan danau yang dilindungi secara hukum adat tersebut.

\section{KESIMPULAN}

1. Danau Bakuok merupakan suaka perikanan yang ditetapkan berdasarkan pada hukum adat (konservasi adat) dan belum dikuatkan dengan Surat Keputusan penetapan sebagai kawasan suaka perikanan oleh Menteri sesuai UndangUndang Republik Indonesia No.31 tahun 2004 tentang perikanan.

2. Sebagai kawasan konservasi, Danau Bakuok belum dilengkapi dokumen resmi yang mengatakan batas dan pembagian wilayah kawasan. Selain itu, penjagaan dan pengelolaan danau dilakukan oleh masyarakat adat dengan sistem penjagaan kolektif.

3. Pengelolaan dan pengawasan Danau Bakuok sebagai konservasi adat terlihat cukup berhasil dibuktikan dengan dipatuhi larangan menangkap ikan di luar musim penangkapan (ma'awuo) dan acara ma'awuo itu sendiri sudah dijadikan sebagai even tahunan tingkat propinsi yang dihadiri oleh Bupati maupun Gubernur.

4. Di danau ini telah dilakukan upaya perbaikan sumber daya ikan dengan melakukan restocking dengan konsep culture base fisheries.

\section{PERSANTUNAN}

Kegiatan dari hasil riset kebijakan pemanfaatan dan konservasi keanekaragaman hayati ikan, T.A. 2007, Pusat Riset Perikanan Tangkap-Ancol, Jakarta. 


\section{DAFTAR PUSTAKA}

Anonimus. 2004a. Undang-Undang Republik Indonesia No.31 tahun 2004 tentang Perikanan. Dewan Perwakilan Rakyat Republik Indoensia.

Anonimus. 2004b. Culture base fisheries Danau Bakuok Kabupaten Kampar. Artikel Harian Riau Tribune. Edisi 24 Nopember.

Anonimus. 2005. Menangkap ikan bersama jelang Ramadhan. Artikel Harian Kompas. 26 September.

Anonimus. 2007. Maawuo, tidak sekadar menjala ikan. http://www.fishyforum.com/.

Anonimus. 2008. Danau Bakuok. http:// www.wisatamelayu.com/.

Dahril, T. 2007. Kebijakan pembangunan perikanan dan kelautan di Propinsi Riau. Materi Presentasi. Dinas Perikanan dan Kelautan Propinsi Riau.
De Silva, S. S. 2002. Culture Based Fisheries. An Underutilised Opportunity in Aquaculture Development. Aquaculture. Elsevier.

Hartoto, D. I., A. S. Sarnita, D. S. Sjafei, A. Satya, Y. Syawal, Sulastri, M. M. Kamal, \& Yudistira Siddik. 1998. Kriteria Evaluasi Suaka Perikanan Perairan Darat. Lembaga IImu Pengetahuan Indoensia. Pusat Penelitian dan Pengembangan Limnologi. Cibinong.

Utomo, A. D., Asyari, \& S. Nurdawati. 2001. Peranan suaka perikanan dalam meningkatkan produksi dan pelestarian sumber daya perikanan perairan umum (Studi kasus di suaka perikanan suak buaya, lubuk lampam, Kabupaten Ogan Komering Ilir, Sumatera Selatan). Jurnal Penelitian Perikanan Indonesia. Vol.7 No.1.

Welcomme. 1979. Fisheries Ecology Floodplain River. Longman. London. 